OPEN ACCESS

Edited by:

Caroline Elizabeth Childs, University of Southampton,

United Kingdom

Reviewed by:

Heather Medbury,

University of Sydney, Australia

Vera Lucia Magalhaes Barbosa,

Brigham and Women's Hospital,

United States

*Correspondence:

Ahmad Aljada

aljadaa@ksau-hs.edu.sa

Specialty section:

This article was submitted to

Nutritional Immunology,

a section of the journal

Frontiers in Immunology

Received: 11 June 2017

Accepted: 26 September 2017

Published: 23 October 2017

Citation:

Alshahrani A, Bin Khunayfir $A$, Al Rayih M, Al Sayed H, Alsadoon A,

Al Dubayee M, Zahra M,

Alrumayyan Y, Al Zayer M, Nasr A and Aljada A (2017)

Phenotypic Characterization

of Human Monocytes

following Macronutrient Intake in Healthy Humans.

Front. Immunol. 8:1293.

doi: 10.3389/fimmu.2017.01293

\section{Phenotypic Characterization of Human Monocytes following Macronutrient Intake in Healthy Humans}

\author{
Awad Alshahrani', Abdalmalik Bin Khunayfir', Mohammed Al Rayih', \\ Hasan Al Sayed', Abdullah Alsadoon', Mohammed Al Dubayee', Mahmoud Zahra', \\ Yousof Alrumayyan', Maha Al Zayer ${ }^{1}$, Amre Nasr ${ }^{1}$ and Ahmad Aljada',2* \\ 'Department of Basic Medical Sciences, King Saud bin Abdulaziz University for Health Sciences, Riyadh, Saudi Arabia, \\ ${ }^{2}$ King Abdullah International Medical Research Center (KAIMRC), Ministry of National Guard Health Affairs (MNGHA), \\ Riyadh, Saudi Arabia
}

Background: Three subsets of human monocytes in circulation have been identified and their characterization is still ill-defined. Although glucose and lipid intakes have been demonstrated to exert pro-inflammatory effects on mononuclear cells (MNCs) of healthy subjects, characterization of monocytes phenotypes following macronutrient (glucose, protein, and lipid) intake in humans remains to be determined.

Methods: Thirty-six healthy, normal weight volunteers were recruited in the study. Subjects were randomly assigned into three groups, each group consisting of 12 participants. Each group drank equal calories (300 kcal) of either glucose or lipids or whey proteins. Each subject served as his own control by drinking $300 \mathrm{~mL}$ of water 1 week before or after the caloric intake. Baseline blood samples were drawn at 0, 1, 2, and 3-h intervals post caloric or water intakes. MNCs were isolated, and the expression levels of different cluster of differentiation (CD) markers (CD86, CD11c, CD169, CD206, CD163, CD36, CD68, CD11b, CD16, and CD14) and IL-6 were measured by RT-qPCR.

Results: Equicaloric intake of either glucose or lipids or whey proteins resulted in different monocyte phenotypes as demonstrated by changes in the expression levels of CD and polarization markers. Whey proteins intake resulted in significant mRNA upregulation in MNCs of CD68 and CD11b at 1, 2, and $3 \mathrm{~h}$ post intake while mRNA of IL-6 was significantly inhibited at $1 \mathrm{~h}$. Lipids intake, on the other hand, resulted in mRNA upregulation of CD1 $1 \mathrm{~b}$ at 2 and $3 \mathrm{~h}$ and CD206 at 1, 2, and $3 \mathrm{~h}$. There were no significant changes in the other CD markers measured (CD86, CD163, CD169, CD36, CD16, and CD14) following either whey proteins or lipids intakes. Glucose intake did not alter mRNA expression of any marker tested except CD206 at $3 \mathrm{~h}$.

Conclusion: Macronutrient intake alters the expression levels of polarization markers in MNCs of human subjects. A distinct population of different monocytes phenotypes may result in human circulation following the intake of different macronutrients. Further studies are required to characterize the immunomodulatory effects of macronutrients intake on monocytes phenotypes and their characteristics in humans.

Keywords: mononuclear cells, monocyte polarization, monocytes subsets, macronutrient intake, whey proteins 


\section{INTRODUCTION}

In recent years, three subsets of human monocytes in circulation have been identified based on the expression of the surface markers CD14 and CD16 (1). The specific roles for these subsets in homeostasis and inflammation are still unclear. Additionally, the characterization of these subsets of human monocytes is still ill-defined and in its infancy. The classical monocytes represent the major population of human monocytes $(90 \%)$ and express high levels of CD14 and lack CD16 expression (high CD14 and no CD16). The other remaining $10 \%$ of human monocytes population is subdivided into the intermediate subset (high CD14 and low CD16) and the non-classical subset (relatively lower CD14 expression and high CD16) (1).

Macrophages differentiate from circulating monocytes. The dynamic recruitment of circulating monocyte into peripheral tissue occurs in response to chemical signals linked to infection, necrosis, or trauma, effectively mobilizing immature monocytes from the circulation to tissue and promoting their differentiation into mature tissue-specific macrophages (2). Mature tissue-specific macrophages express receptors that interact with their local chemical environment. This includes fate-determining growth factors, pro-inflammatory cytokines, and microbial components. Cytokine-receptor interactions dramatically alter macrophage physiology, signaling the expression of different surface receptors, and the secretion of pro-inflammatory mediators and cytokines. During inflammation, specific reciprocal interactions between macrophages and $\mathrm{T}$ and $\mathrm{B}$ cells (via cytokines-receptor interaction) promote further activation, enhanced regulation, and the acquisition of specific functional phenotypes (3). There are three main macrophage phenotypes: a pro-inflammatory (M1), an antiinflammatory pro-tissue (M2), and metabolically activated $(\mathrm{MMe})$ macrophage phenotypes $(3,4)$. The classically activated macrophages are triggered by Th1-derived interferon-gamma (IFN $\gamma$ ) and lipopolysaccharides (LPS) $(5,6)$. LPS and IFN $\gamma$ polarize resident macrophages (M0) toward the M1 subtype, which secretes pro-inflammatory cytokines such as tumor necrosis factor (TNF $\alpha)$, IL-1, and IL-6. These cytokines are implicated in initiating and sustaining inflammatory function (7). M1 macrophages, therefore, mediate intracellular killing of pathogens and produce microbicidal reactive nitrogen and oxygen intermediates that promote inflammation. Furthermore, M1 macrophages express unique surface markers such as CD80 and CD86. On the other hand, interleukin-4 (IL-4) and IL-13 induced different or "alternative" activation for macrophages, largely by inhibiting the expression of the major surface markers usually found in classically activated macrophages (8). IL-4 and IL-13 induce macrophage polarization into the M2 subtype, which produces anti-inflammatory cytokines such as IL-10. M2 macrophages are characterized by strong IgE response and are involved in fungal and parasitic infections and tissue remodeling (3). These two phenotypes metabolize arginine differently. M1 macrophages convert arginine to nitric oxide (NO), whereas M2 macrophages convert arginine to ornithine $(9,10)$. NO has microbicidal functions and can damage lipids, proteins, and DNA and inhibits cell division, while ornithine stimulates cell division and wound healing $(11,12)$. This finding led to the consensus of the pro-inflammatory versus anti-inflammatory properties of M1/M2 macrophages.

Macronutrient intake has been shown to induce inflammation (13). Glucose and saturated fat (cream)-induced reactive oxygen species (ROS) generation in mononuclear cells (MNCs), which subsequently could lead to lipid, protein, and DNA damage $(14,15)$. A mixed meal from a fast food chain also induces oxidative stress and inflammation at the cellular and molecular level (16). These data suggest an M1-like monocytes form following macronutrient intake. Interestingly, Kratz et al. recently identified a distinct population of metabolically activated macrophages (MMe) in adipose tissue, following glucose activation (4). MMe do not express the classic markers of M1 cells, suggesting that macrophages might express different phenotypical markers when metabolically stimulated (by glucose, insulin, or palmitate). In this study, we examined monocyte polarization following equicaloric intake of macronutrients (glucose, whey proteins, and lipids) in healthy lean subjects. We hypothesized that different macronutrients could induce different immunomodulatory effects resulting in distinct metabolically activated monocytic phenotypes similar to MMe.

\section{MATERIALS AND METHODS}

\section{Subjects}

Thirty-six normal healthy adult volunteers (male: 35 , female: 1 ; age range: $20-25$ years; mean: $21.4 \pm 0.18$ years; mean \pm SEM) of normal weight (BMI-glucose group: $21.5 \pm 0.59 \mathrm{~kg} / \mathrm{m}^{2}$; BMI-proteins group: $22.4 \pm 0.59 \mathrm{~kg} / \mathrm{m}^{2}$; BMI-lipids group: $22.0 \pm 0.46 \mathrm{~kg} / \mathrm{m}^{2} ;$ mean $\pm \mathrm{SEM}$ ) were recruited into the study. All were normotensive, had a normal lipid profile, normal renal, and liver function tests, and were not on any medications. The 36 participants were randomly assigned by the primary investigator (PI) following simple randomization procedure (computerized random numbers) to three different groups; each received one type of macronutrient (glucose, whey proteins, or lipids). Following an overnight fast, a baseline blood sample was taken. Subjects were then given either 300 calories of glucose (NERL Trutol 75) or lipids (90 g whipping cream, $31.5 \mathrm{~g}$ fat, $1.7 \mathrm{~g}$ protein, and $2.25 \mathrm{~g}$ carbohydrate) or protein [isopure unflavored whey proteins isolate (WPI) powder containing 26 g per serving of $100 \%$ WPI, stripped of fat, carbs, fillers, sugars, and lactose] solution over $5 \mathrm{~min}$. Cream and protein preparations were diluted with water up to $300 \mathrm{~mL}$ solutions. Further blood samples were obtained at 1,2 , and $3 \mathrm{~h}$ after the macronutrient intake. Subjects, either 1 week before or after the macronutrient challenge, were given $300 \mathrm{~mL}$ of water to drink in the fasting state. Blood samples were obtained before and at 1,2 , and $3 \mathrm{~h}$ after water intake as well. Each subject served as his/her own control and was randomly given macronutrient or water intake. All subjects gave their written, informed consent. Institutional Review Board (IRB) of the Ministry of National Guard Health Affairs (MNGHA) approved the study protocol. Recruitment of the subjects was done in February 2016, and the collection of samples was concluded on April 2016. The study was conducted 
at College of Medicine, King Saud bin Abdulaziz University for Health Sciences, Riyadh, Kingdom of Saudi Arabia.

\section{Isolation of MNCs}

Blood samples were collected in Na-EDTA as an anticoagulant. Fifteen milliliters of the anticoagulated blood sample were diluted with an equal volume of PBS and were carefully layered over $50 \mathrm{~mL}$ of Ficoll-Hypaque (50 mL Leucosep Tubes, Greiner BioOne North America Inc., NC, USA). Samples were centrifuged at $450 \times g$, in a swing out rotor for $30 \mathrm{~min}$ at $22^{\circ} \mathrm{C}$. At the end of the centrifugation, MNCs separate out at the top of the RBC pellet. MNC bands were harvested with a pipette, repeatedly washed with PBS. Fifty microliters of Qiagen RNAlater were added to the pellets and samples were then frozen at $-80^{\circ} \mathrm{C}$.

\section{Glucose and Insulin Measurements}

Whole blood glucose levels were measured using ACCU Check Active Blood Glucose Monitor. Serum insulin concentration was determined using ALPCO insulin ELISA kit (Salem, NH, USA) according to the manufacturer's protocol. Twenty-five microliters of standards, controls, and samples were added to the microplate wells with the detection antibody. The microplate was then incubated on a microplate shaker at 700-900 rpm followed by washing with Wash Buffer. TMB Substrate was then added, and the microplate was incubated a second time on a microplate shaker followed by stop solution, and the optical density was measured by a spectrophotometer at $450 \mathrm{~nm}$.

\section{mRNA Quantification by Real-time RT-PCR}

Total RNA was isolated using the Ambion Aqueous kit (Ambion). The quality and quantity of the isolated RNA were determined using a The Agilent 2100 Bioanalyzer system. Then, $1 \mu \mathrm{g}$ of total RNA was reverse-transcribed using first strand cDNA synthesis Kit (Millipore, USA). Real-time RT-PCR was performed with a 7900HT Fast Real-Time PCR System (Applied Biosystems, USA), using $2 \mu \mathrm{L}$ cDNA, $10 \mu \mathrm{L} 2 \mathrm{X}$ Sybergreen Master mix [150 mM Tris, $\mathrm{pH}$ 9.2, $40 \mathrm{mM}\left(\mathrm{NH}_{4}\right)_{2} \mathrm{SO}_{4}, 5 \mathrm{mM} \mathrm{MgCl}$, 0.02\% Tween-20, $0.4 \mathrm{mM}$ dNTPs, $1.25 \mathrm{U}$ Taq Polymerase, $1 \times$ Sybergreen] and $0.5 \mu \mathrm{L}$ of $20 \mu \mathrm{M}$ gene-specific primers
(Table 1). The specificity and size of the PCR products were tested by adding a melt curve at the end of the amplifications, analysis on a $2 \%$ agarose gel, and sequencing of the bands. All values were normalized to cyclophylin A and RPL-13. The $2^{-\triangle \Delta C T}$ method was used for relative quantification for qRT-PCR experiments (17). Baseline expression levels of markers studied for each subject was normalized to a 0 value. Positive values indicate an upregulation while negative values indicate an inhibition in mRNA expression.

\section{Statistical Analysis}

Statistical analysis was carried out using SigmaStat software ver. 3.0 (Jandel Scientific, San Rafael, CA, USA). Fold change in mRNA expression was calculated for qRT-PCR results and analysis was carried out with one-factor ANOVA for the repeated measures using Dunnett's test for comparisons against the baseline $(0 \mathrm{~h})$ for normally distributed data. Dunn's test was used for the non-parametric data. A $P$-value $<0.05$ was used to assess significance for all statistical analyses. Results are presented as mean \pm SEM.

\section{RESULTS}

Caloric intake $(300 \mathrm{kcal})$ of macronutrients (glucose, proteins, lipids) in normal volunteers changed insulin and blood glucose significantly (Figure 1). Glucose intake increased insulin concentrations at 1 and $2 \mathrm{~h}$ while whey proteins intake increased insulin concentrations at $1-3 \mathrm{~h}\left({ }^{\star} P<0.05\right.$; Figures $\left.\mathbf{1 A}, \mathbf{B}\right)$. There were no changes in insulin concentrations following lipids intake. Whey proteins intake decreased blood glucose significantly at hours 1 , 2 , and $3\left({ }^{*} P<0.05\right.$; Figure 1D); whereas, blood glucose concentration was decreased at 2 and $3 \mathrm{~h}$ following glucose and lipid intakes. Whey proteins intake resulted in a significant mRNA expression increase in CD68 and CD11b at 1,2, and $3 \mathrm{~h}$ post intake ( ${ }^{\star} P<0.05$; Figures 2 and 3 ) and mRNA downregulation of IL-6 in MNCs ( ${ }^{\star} P<0.05$; Figure 4$)$ suggesting M2 like monocyte polarization. However, there were no significant changes in CD206, CD86, CD163, CD169, CD36, CD16, and CD14 following whey proteins intake (Figure 5B; Table 2). Lipids, on the other hand, induced the expression of CD11b mRNA in MNCs (Figure 3C) and CD206 (Figure 5C). There were no significant
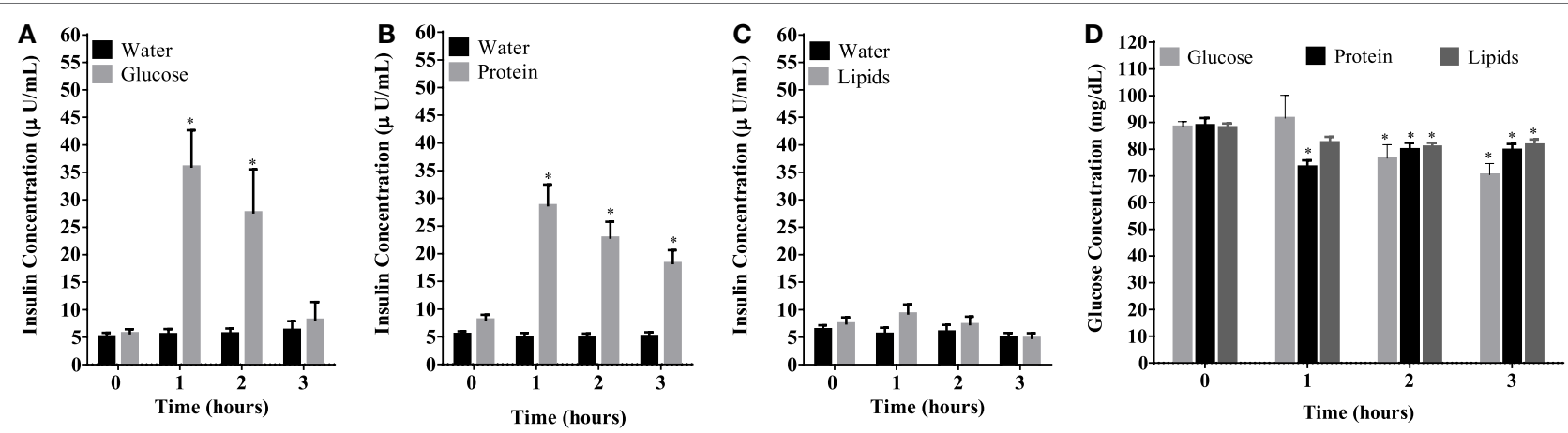

FIGURE 1 | Plasma insulin concentrations (microunits per microliters) (A-C) and whole blood glucose concentrations (D) at $0,1,2$, and $3 \mathrm{~h}$ post macronutrient intake; $n=12$ per group; ${ }^{*} P<0.05$. 

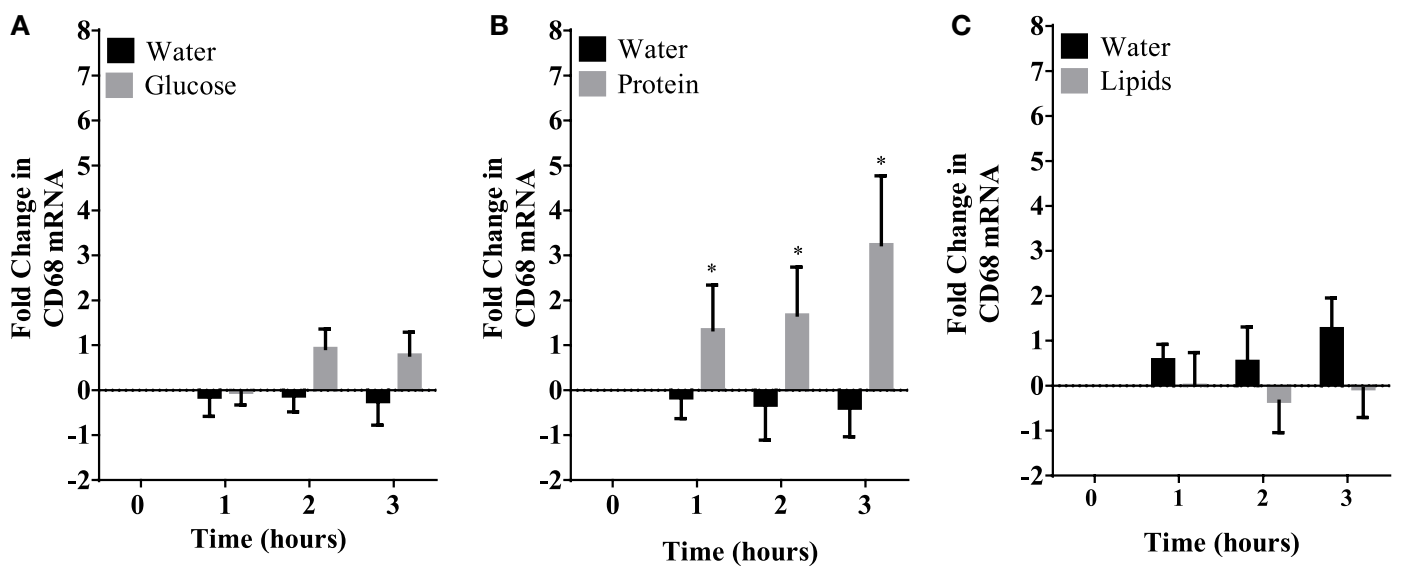

FIGURE 2 | Fold change in mRNA expression of CD68 in mononuclear cells following equicaloric intake of macronutrients. Glucose (A) and lipids (B) did not change mRNA expression of CD68 significantly while whey proteins intake (C) induced mRNA expression of CD68 at 1, 2, and $3 \mathrm{~h}$ post macronutrient challenge; $n=12$ per group; ${ }^{*} P<0.05$.
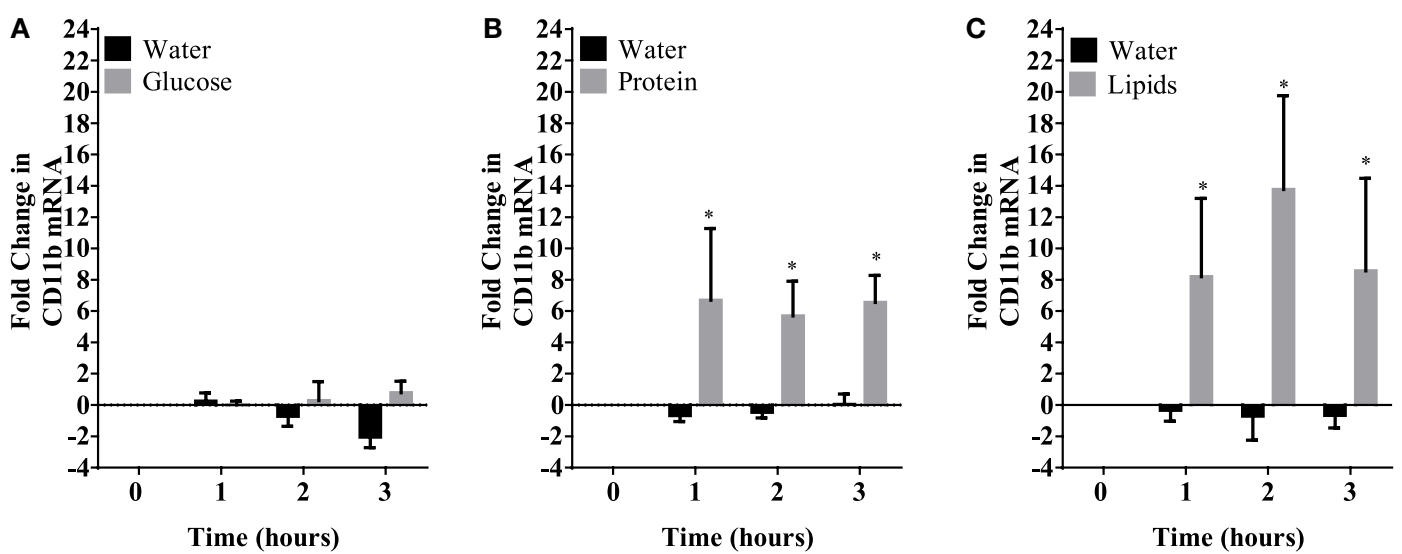

FIGURE 3 | Fold change in mRNA expression of CD11b in mononuclear cells following equicaloric intake of macronutrients. Glucose (A) had no effect on CD11b mRNA expression while both whey proteins $\mathbf{( B )}$ and lipids $\mathbf{( C )}$ induced mRNA expression of CD11b significantly; $n=12$ per group; ${ }^{*} P<0.05$.
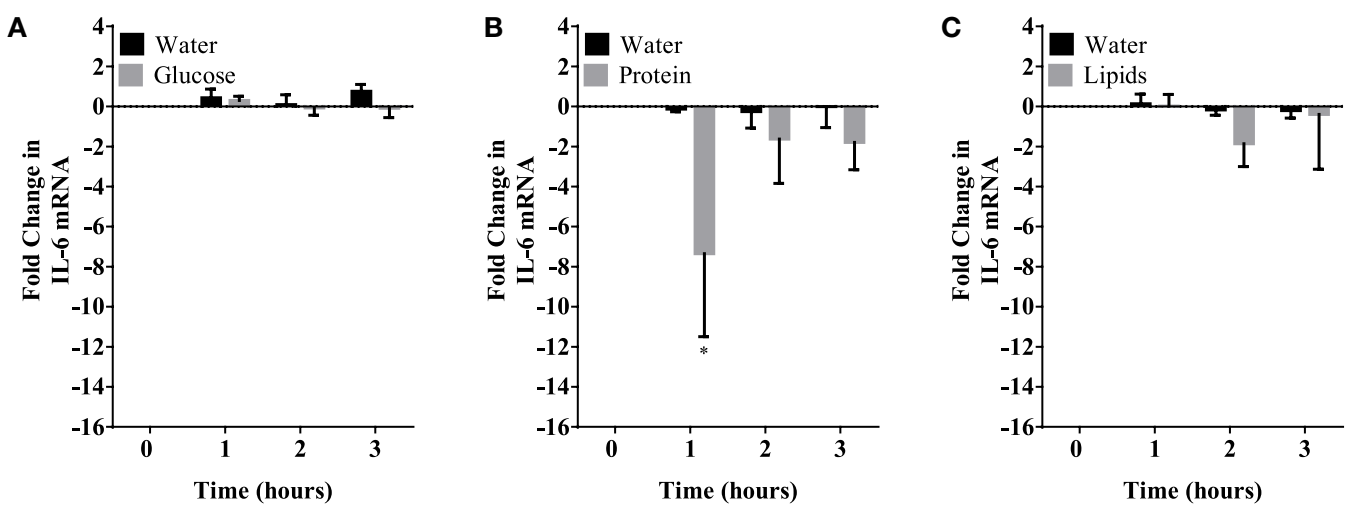

FIGURE 4 | IL-6 mRNA expression levels in mononuclear cells (MNCs) following glucose (A), whey proteins (B), and lipids (C). There was significant inhibition in IL-6 mRNA expression in MNCS following whey proteins intake; $n=12$ per group; ${ }^{\star} P<0.05$. 

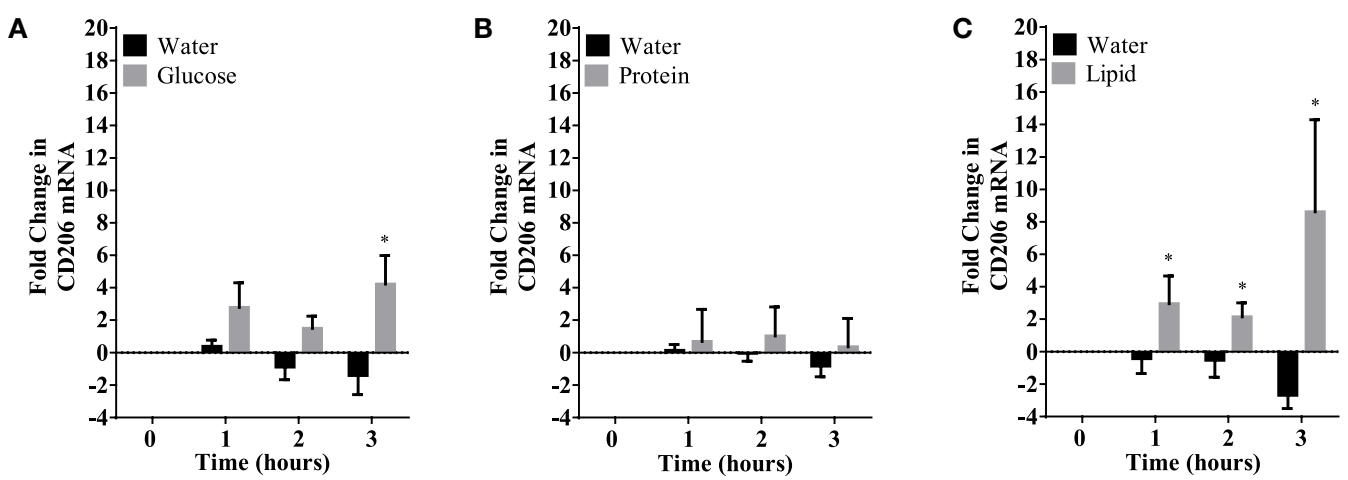

FIGURE 5 | CD206 mRNA expression changes in mononuclear cells following macronutrient intake of glucose (A), whey proteins (B), and lipids (C). Glucose intake induced significant changes at $3 \mathrm{~h}$ post glucose intake while lipids intake induced significant changes $1-3 \mathrm{~h}$ post challenge; $n=12$ per group; ${ }^{\star} P<0.05$.

TABLE 1 | Primer sequences for all primers used in qRT-PCR.

\begin{tabular}{|c|c|c|c|}
\hline Primer & Sense $\left(5^{\prime} \rightarrow 3^{\prime}\right)$ & Anti sense $\left(5^{\prime} \rightarrow 3^{\prime}\right)$ & Accession number \\
\hline CD206 & TTCGGACACCCATCGGAATाT & CACAAGCGCTGCGTGGAT & NM_002438.3 \\
\hline CD86 & CTGCTCATCTATACACGGTTACC & GGAAACGTCGTACAGTTCTGTG & NM_175862.4 \\
\hline CD11b & CAGCCTITGACCTTATGTCATGG & CCTGTGCTGTAGTCGCACT & NM_001145808.1 \\
\hline CD68 & GCTACATGGCGGTGGAGTACAA & ATGATGAGAGGCAGCAAGATGG & NM_001251.2 \\
\hline CD169 & CCTCGGGGAGGAACATCCTT & AGGCGTACCCCATCCTTGA & NM_023068.3 \\
\hline IL-6 & AATAACCACCCCTGACCCAAC & AATCTGAGGTGCCCATGCTAC & NM_000600.4 \\
\hline CD163 & CAGGAAACCAGTCCCAAACA & AGCGACCTCCTCCATTTACC & NM_004244.5 \\
\hline CD36 & GCCAAGGAAAATGTAACCCAGG & GCCTCTGTTCCAACTGATAGTGA & NM_001001548.2 \\
\hline CD14 & AGCCAAGGCAGTITGAGTCC & TAAAGGACTGCCAGCCAAGC & NM_000591.3 \\
\hline CD16 & ATGTGTCTTCAGAGACTGTGAAC & TITATGGTCCTTCCAGTCTCTTG & NM_000569.7 \\
\hline RPL13 & AACAAGTTGAAGTACCTGGCTIC & TGGTाTGTGGGGCAGCATA & NM_000977.3 \\
\hline Cyclophilin A & CCC ACC GTG TTC TTC GAC AT & गा CTG CTG TCT ПTG GGA CCT T & NM_021130.4 \\
\hline
\end{tabular}

TABLE 2 | Fold change in mRNA expression of CD86, CD163, CD169, CD36, CD14, and CD16 in mononuclear cells of normal volunteers following equicaloric intake of glucose, whey proteins, and lipids.

\begin{tabular}{|c|c|c|c|c|}
\hline & \multirow{2}{*}{$\begin{array}{l}\text { Fold change in mRNA expression } \\
\qquad(\text { mean } \pm \text { SEM) }\end{array}$} & \multicolumn{3}{|c|}{ Time (h) } \\
\hline & & 1 & 2 & 3 \\
\hline \multirow[t]{6}{*}{ Glucose intake } & CD86 & $-0.020 \pm 0.184$ & $-0.292 \pm 0.120$ & $-0.600 \pm 0.234$ \\
\hline & CD163 & $0.604 \pm 0.598$ & $-0.401 \pm 0.498$ & $0.556 \pm 0.350$ \\
\hline & CD169 & $0.621 \pm 0.345$ & $-1.128 \pm 0.871$ & $-0.078 \pm 0.499$ \\
\hline & CD36 & $-0.727 \pm 0.59$ & $-0.455 \pm 0.314$ & $0.218 \pm 0.434$ \\
\hline & CD14 & $-0.657 \pm 0.387$ & $-0.247 \pm 0.164$ & $-0.292 \pm 0.241$ \\
\hline & CD16 & $-0.633 \pm 1.640$ & $-1.508 \pm 4.174$ & $-0.645 \pm 0.675$ \\
\hline \multirow[t]{6}{*}{ Whey proteins intake } & CD86 & $0.313 \pm 0.535$ & $0.178 \pm 0.412$ & $0.332 \pm 0.514$ \\
\hline & CD163 & $-0.581 \pm 0.569$ & $0.113 \pm 0.925$ & $-0.771 \pm 0.503$ \\
\hline & CD169 & $0.295 \pm 0.653$ & $-0.315 \pm 0.776$ & $-0.130 \pm-0.597$ \\
\hline & CD36 & $-0.477 \pm 0.496$ & $-0.181 \pm 0.424$ & $-0.265 \pm 0.526$ \\
\hline & CD14 & $-0.714 \pm 0.790$ & $-0.335 \pm 0.328$ & $-0.473 \pm 0.282$ \\
\hline & CD16 & $-0.695 \pm 0.995$ & $2.838 \pm 2.441$ & $4.900 \pm 4.560$ \\
\hline \multirow[t]{6}{*}{ Lipids intake } & CD86 & $0.290 \pm 0.713$ & $-0.193 \pm 0.594$ & $0.001 \pm 0.794$ \\
\hline & CD163 & $0.325 \pm 0.725$ & $-0.279 \pm 0.533$ & $0.648 \pm 0.739$ \\
\hline & CD169 & $-0.359 \pm 0.722$ & $-2.012 \pm 1.271$ & $-0.518 \pm 0.446$ \\
\hline & CD36 & $-0.002 \pm 0.187$ & $-0.129 \pm 0.163$ & $0.573 \pm 0.613$ \\
\hline & CD14 & $-0.681 \pm 0.302$ & $-0.942 \pm 0.658$ & $0.098 \pm 0.72$ \\
\hline & CD16 & $-0.462 \pm 0.485$ & $-0.372 \pm 2.109$ & $1.107 \pm 2.168$ \\
\hline
\end{tabular}

No changes in mRNA expression were also observed following water challenge (data not shown); $n=12$ per group; ${ }^{*} P<0.05$, mean \pm SEM.

changes in mRNA expression of CD68, IL-6, CD86, CD163, CD169, CD36, CD16, and CD14 (Figures 2 and 4; Table 2). Glucose intake changed the mRNA expression levels in MNCs of CD206 at 3 h only $\left({ }^{\star} P<0.05\right.$; Figure 5$)$. Glucose intake did not cause any changes in the mRNA expression of the other macrophage differentiation markers examined in this study. 


\section{DISCUSSION}

The immunomodulatory effect of macronutrients on monocytes phenotypes was observed in healthy humans. Whey proteins intake induced CD68 expression whereas the other macronutrients tested did not change CD68 expression levels. CD11b was also induced following whey proteins intake. Both CD68 and CD11b are also considered a pan-myeloid marker. CD11b is the integrin alpha $\mathrm{M}$ chain and is important for the adherence of neutrophils and monocytes to stimulated endothelium (18). Furthermore, CD11b plays a role in phagocytosis of complement coated particles (19). In addition, IL-6 expression was also inhibited following protein intake suggesting monocyte polarization to the M2 like phenotype. This is consistent with what is known about the protective properties of whey proteins as it promotes weight loss, reduces body fat, maintains muscle mass, reduces blood pressure, improves cardiovascular health, and contributes to satiety control (20-24). Many animal studies have reported that whey proteins intake increases glutathione levels, a potent antioxidant, which can suppress ROS generation in leukocytes (25-27). Other studies demonstrated that whey proteins decrease pro-inflammatory mediators, e.g., IL-6 and TNF- $\alpha$ (27-29). Whey proteins intake induced insulin release as the plasma insulin concentrations increased significantly at $1-3 \mathrm{~h}$. The anti-inflammatory effects of whey proteins could be mediated through insulin release, which exerts anti-inflammatory effects in humans $(13,30-33)$. Glucose, on the other hand, increased insulin concentration up to $2 \mathrm{~h}$ and its pro-inflammatory effects probably counteracted the anti-inflammatory effect of insulin. Further studies are needed to explore this proposed mechanism.

Lipids, in the form of whipping cream, has been shown previously to generate ROS, increase serum LPS, the expression of toll-like receptor- 4 , and markers of inflammation such as NF- $\kappa B$ binding and TNF $\alpha$ in MNCs $(15,34,35)$. The choice of whipping cream was based on the fact that it previously showed positive results and for the convenience of the subjects. Unexpectedly, our results showed that lipids did not induce M1 like monocyte phenotype, but rather induced upregulation of a pan-macrophage marker, CD11b, and a marker of M2 macrophages, CD206. These two findings suggest that there is mild polarization toward the M2 like phenotype, but not as profound as with whey proteins (which inhibited the expression of IL-6, a marker of M1). Our results might be explained by the fact that whipping cream products contains different amounts of saturated fats and monounsaturated fats, which have been shown to activate M1 and M2, respectively. Saturated fats [e.g., palmitate (PA)] have been associated with pro-inflammatory changes in adipose tissue macrophages and can activate TLR4 signaling pathways, inducing pro-inflammatory

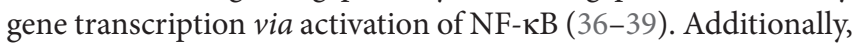
when PA was incubated ex vivo with macrophages, it resulted in elevated expression of pro-inflammatory genes (e.g., IL-6 and $\mathrm{TNF} \alpha$ ), characteristic of the M1 macrophage profile (40). In contrast, palmitoleate, a monounsaturated fatty acid, is secreted by adipose tissue and was shown in vivo to protect against the development of fatty liver and improve insulin sensitivity (41-43). Treatment of macrophages, in vitro, with palmitoleate or oleic acid led to the expression of anti-inflammatory M2 genes such as IL-10 $(40,44,45)$. It is worth mentioning that adding palmitoleate to the macrophages that were already polarized to M1 by palmitate reversed this polarization (40) and adding palmitic acid to a culture of oleic acid-induced M2 macrophages resulted in a complete inhibition of oleic acid-induced markers of M2 cells, Arg1, and CD206 (45). Polyunsaturated fats (PUFA) can elicit different pro-inflammatory (e.g., n-6 PUFA) or anti-inflammatory (e.g., docosahexaenoic acid and eicosapentaenoic acid) profiles, depending on the type of PUFA (46-49). Accordingly, our results showed that whipping cream intake induced mild polarization toward M2 like monocytes, possibly due to the opposing polarizing stimuli. Further studies utilizing different fats are needed to dissect their effects on monocyte subsets differentiation.

In our study, glucose did not induce any of the cluster of differentiation markers measured except CD206 at 3 h. CD206 (also termed as C-type mannose receptor 1) in MNCs is considered a M2 macrophage marker $(50,51)$. However, CD206 function is not yet fully understood. Although it was suggested that CD206 has a role in the resolution of inflammation by clearing inflammatory molecules from the blood (36), macrophages expressing CD206 have unfavorable profibrotic effects. These macrophages promote fibroblast growth through TGF- $\beta$ and chemokine production (52). Additionally, CD206 expressing macrophages may undergo a fibrocyte-like phenotype switch and produce collagen (53). Interestingly, CD206 upregulation was only observed following glucose and lipids intake. There were no changes observed on CD206 levels following whey proteins intake. Although glucose was shown to induce ROS generation and inflammation in MNCs in multiple studies (13), our study showed the lack of M1 surface markers after glucose intake. This unexpected finding, however, is similar to a recent study by Kratz et al. that identified a distinct population of adipose tissue metabolically activated macrophages (MMe) following glucose intake in obese mice and humans (54). In detail, their findings demonstrated that when macrophages are treated with glucose, palmitate, and insulin (metabolic activation), this produces a unique macrophage phenotype that is mechanistically distinct from classically activated macrophages (M1), suggesting that the metabolic activation drives macrophage polarization via mechanisms that are different from the classic activation. These cells do not express the classic markers of M1 or M2 macrophages, suggesting that they might express different phenotypical markers when metabolically stimulated (by glucose or palmitate). Further studies are needed to explore the surface markers on monocytes following glucose challenge.

Human monocytes in circulation have been classified into three subsets based on the expression of the surface markers CD14 and CD16 (1). However, macronutrients intake did not change the expression levels of CD14 and CD16 in human monocytes significantly suggesting the polarization of monocytes to different subsets of monocytes than the classical and non-classical monocytes characterized by CD14 and CD16. The characterization of these subsets of human monocytes is still ill-defined and further studies are needed to elucidate their characteristics. One of the limitations of our study is that it was performed on healthy subjects only. Future studies on the obese population may yield different results as obesity is associated 
with higher levels of subclinical inflammation and is associated with insulin resistance. Furthermore, MNCs represent a mixture of cells (monocytes, B cells, and T cells). This heterogeneity of cells utilized in this study represents a significant shortcoming in this study as large quantities of blood are needed to conduct such studies. Characterization of pure human monocyte phenotypes following macronutrients intake would be a better approach.

\section{CONCLUSION}

Macronutrients induce different monocytes subtypes in human circulation with different phenotypical markers. A distinct population of MMe-like monocytes may appear in human circulation following different macronutrient intake. Whey proteins polarize monocytes to M2-like characteristics, evident by the higher levels of CD68 and CD11b and lower levels of IL-6. Lipids intake polarizes monocytes to another subset with higher levels of CD206 and CD11b. Glucose, on the other hand, induces monocytes subsets with higher levels of CD206. Examination of other macrophage differentiation markers following macronutrients intake is needed to further characterize monocytes subsets that result from different macronutrients intake. Studying the effects of the immunomodulatory effects of different macronutrients on monocyte phenotypes could open new possibilities for the identification of different nutrients controlling the metabolic activation of immune cells.

\section{REFERENCES}

1. Ziegler-Heitbrock L, Ancuta P, Crowe S, Dalod M, Grau V, Hart DN, et al. Nomenclature of monocytes and dendritic cells in blood. Blood (2010) 116:e74-80. doi:10.1182/blood-2010-02-258558

2. Italiani P, Boraschi D. From monocytes to M1/M2 macrophages: phenotypical vs. functional differentiation. Front Immunol (2014) 5:1-22. doi:10.3389/ fimmu.2014.00514

3. Martinez FO, Gordon S. The M1 and M2 paradigm of macrophage activation: time for reassessment. F1000Prime Rep (2014) 6:13. doi:10.12703/P6-13

4. Kratz M, Coats BR, Hisert KB, Hagman D, Mutskov V, Peris E, et al. Metabolic dysfunction drives a mechanistically distinct proinflammatory phenotype in adipose tissue macrophages. Cell Metab (2014) 20:614-25. doi:10.1016/j.cmet.2014.08.010

5. Guha M, Mackman N. LPS induction of gene expression in human monocytes. Cell Signal (2001) 13:85-94. doi:10.1016/S0898-6568(00)00149-2

6. Billiau A, Matthys P. Interferon-gamma: a historical perspective. Cytokine Growth Factor Rev (2009) 20:97-113. doi:10.1016/j.cytogfr.2009.02.004

7. Feghali CA, Wright TM. Cytokines in acute and chronic inflammation. Front Biosci (1997) 2:d12-26. doi:10.2741/A171

8. Stein M, Keshav S, Harris N, Gordon S. Interleukin 4 potently enhances murine macrophage mannose receptor activity: a marker of alternative immunologic macrophage activation. J Exp Med (1992) 176:287-92. doi:10.1084/ jem.176.1.287

9. MacMicking J, Xie QW, Nathan C. Nitric oxide and macrophage function. Annu Rev Immunol (1997) 15:323-50. doi:10.1146/annurev.immunol.15.1.323

10. Munder M, Eichmann K, Morán JM, Centeno F, Soler G, Modolell M. Th1/ Th2-regulated expression of arginase isoforms in murine macrophages and dendritic cells. J Immunol (1999) 163:3771-7.

11. Albina JE, Mills CD, Henry WL, Caldwell MD. Temporal expression of different pathways of 1-arginine metabolism in healing wounds. J Immunol (1990) 144:3877-80.

12. Nathan CF, Hibbs JB. Role of nitric oxide synthesis in macrophage antimicrobial activity. Curr Opin Immunol (1991) 3:65-70. doi:10.1016/09527915(91)90079-G

\section{ETHICS STATEMENT}

The proposal has been reviewed and approved by the Institutional Review Board (IRB) at King Abdulaziz Medical City with an IRB number SP15/026 on the 15th of June 2015.

\section{AUTHOR CONTRIBUTIONS}

All authors contributed extensively to the manuscript and assumed full responsibility for its content. AALS, MD, and AALJ conceived the proposal study design and analyzed data and contributed to the writing of this manuscript. AK, MA, AALS, and HS designed and performed experiments, analyzed data, and assisted in paper writing. MZ and AN supervised the project and performed several of the assays in this study. MZ and YA assisted in sample collection and developed and executed several assays. All authors assisted in manuscript preparation.

\section{ACKNOWLEDGMENTS}

This work was supported by King Abdullah International Medical Research Center (KAIMRC); Ministry of National Guard Health Affairs (MNGHA) and conducted at College of Medicine, King Saud bin Abdulaziz University for Health Sciences, Riyadh, Kingdom of Saudi Arabia, and is registered under clinicaltrials. gov (ID: NCT03173677).

13. Dandona P, Ghanim H, Chaudhuri A, Dhindsa S, Kim SS. Macronutrient intake induces oxidative and inflammatory stress: potential relevance to atherosclerosis and insulin resistance. Exp Mol Med (2010) 42:245-53. doi:10.3858/emm.2010.42.4.033

14. Mohanty P, Hamouda W, Garg R, Aljada A, Ghanim H, Dandona P. Glucose challenge stimulates reactive oxygen species (ROS) generation by leucocytes. J Clin Endocrinol Metab (2000) 85:2970-3. doi:10.1210/jcem.85. 8.6854

15. Mohanty P, Ghanim H, Hamouda W, Aljada A, Garg R, Dandona P. Both lipid and protein intakes stimulate increased generation of reactive oxygen species by polymorphonuclear leukocytes and mononuclear cells. Am J Clin Nutr (2002) 75:767-72.

16. Aljada A, Mohanty P, Ghanim H, Abdo T, Tripathy D, Chaudhuri A, et al. Increase in intranuclear nuclear factor kappaB and decrease in inhibitor kappaB in mononuclear cells after a mixed meal: evidence for a proinflammatory effect. Am J Clin Nutr (2004) 79:682-90.

17. Livak KJ, Schmittgen TD. Analysis of relative gene expression data using real-time quantitative PCR and the 2(-delta delta $\mathrm{C}(\mathrm{T})$ ) method. Methods (2001) 25:402-8. doi:10.1006/meth.2001.1262

18. Muller WA. Getting leukocytes to the site of inflammation. Vet Pathol (2013) 50:7-22. doi:10.1177/0300985812469883

19. Le Cabec V, Carreno S, Moisand A, Bordier C, Maridonneau-Parini I. Complement receptor 3 (CD11b/CD18) mediates type I and type II phagocytosis during nonopsonic and opsonic phagocytosis, respectively. J Immunol (2002) 169:2003-9. doi:10.4049/jimmunol.169.4.2003

20. Bowen J, Noakes M, Clifton PM. Appetite regulatory hormone responses to various dietary proteins differ by body mass index status despite similar reductions in ad libitum energy intake. J Clin Endocrinol Metab (2006) 91:2913-9. doi:10.1210/jc.2006-0609

21. Frestedt JL, Zenk JL, Kuskowski MA, Ward LS, Bastian ED. A whey-protein supplement increases fat loss and spares lean muscle in obese subjects: a randomized human clinical study. Nutr Metab (2008) 5:8-8. doi:10.1186/ 1743-7075-5-8

22. Pichon L, Potier M, Tome D, Mikogami T, Laplaize B, Martin-Rouas C, et al. High-protein diets containing different milk protein fractions 
differently influence energy intake and adiposity in the rat. Br J Nutr (2008) 99:739-48. doi:10.1017/S0007114507831709

23. Pal S, Ellis V. The chronic effects of whey proteins on blood pressure, vascular function, and inflammatory markers in overweight individuals. Obesity (2010) 18:1354-9. doi:10.1038/oby.2009.397

24. Baer DJ, Stote KS, Paul DR, Harris GK, Rumpler WV, Clevidence BA. Whey protein but not soy protein supplementation alters body weight and composition in free-living overweight and obese adults. J Nutr (2011) 141: 1489-94. doi:10.3945/jn.111.139840

25. Lands LC, Grey VL, Smountas AA. Effect of supplementation with a cysteine donor on muscular performance. J Appl Physiol (1999) 87:1381-5.

26. Bounous G. Whey protein concentrate (WPC) and glutathione modulation in cancer treatment. Anticancer Res (2000) 20:4785-92.

27. Ebaid H, Badr G, Metwalli A. Immunoenhancing property of dietary undenatured whey protein derived from three camel breeds in mice. Biologia (2012) 67:425-33. doi:10.2478/s11756-012-0014-0

28. Kume H, Okazaki K, Sasaki H. Hepatoprotective effects of whey protein on D-galactosamine-induced hepatitis and liver fibrosis in rats. Biosci Biotechnol Biochem (2006) 70:1281-5. doi:10.1271/bbb.70.1281

29. Ebaid H, Salem A, Sayed A, Metwalli A. Whey protein enhances normal inflammatory responses during cutaneous wound healing in diabetic rats. Lipids Health Dis (2011) 10:235-235. doi:10.1186/1476-511X-10-235

30. Dandona P, Aljada A, Mohanty P, Ghanim H, Hamouda W, Assian E, et al. Insulin inhibits intranuclear nuclear factor kappaB and stimulates IkappaB in mononuclear cells in obese subjects: evidence for an anti-inflammatory effect? J Clin Endocrinol Metab (2001) 86:3257-65. doi:10.1210/jcem.86. 7.7623

31. Chaudhuri A, Janicke D, Wilson MF, Tripathy D, Garg R, Bandyopadhyay A, et al. Anti-inflammatory and profibrinolytic effect of insulin in acute ST-segment-elevation myocardial infarction. Circulation (2004) 109:849-54. doi:10.1161/01.CIR.0000116762.77804.FC

32. Dandona P, Aljada A, O'Donnell A, Dhindsa S, Garg R. Insulin is an antiinflammatory and anti-atherosclerotic hormone. Metab Syndr Relat Disord (2004) 2:137-42. doi:10.1089/met.2004.2.137

33. Dandona P, Mohanty P, Chaudhuri A, Garg R, Aljada A. Insulin infusion in acute illness. J Clin Invest (2005) 115:2069-72. doi:10.1172/JCI26045

34. Ghanim H, Abuaysheh S, Sia CL, Korzeniewski K, Chaudhuri A, FernandezReal JM, et al. Increase in plasma endotoxin concentrations and the expression of toll-like receptors and suppressor of cytokine signaling-3 in mononuclear cells after a high-fat, high-carbohydrate meal: implications for insulin resistance. Diabetes Care (2009) 32:2281-7. doi:10.2337/ dc09-0979

35. Deopurkar R, Ghanim H, Friedman J, Abuaysheh S, Sia CL, Mohanty P, et al. Differential effects of cream, glucose, and orange juice on inflammation, endotoxin, and the expression of toll-like receptor-4 and suppressor of cytokine signaling-3. Diabetes Care (2010) 33:991-7. doi:10.2337/ dc09-1630

36. Lee SJ, Evers S, Roeder D, Parlow AF, Risteli J, Risteli L, et al. Mannose receptor-mediated regulation of serum glycoprotein homeostasis. Science (2002) 295:1898-901. doi:10.1126/science.1069540

37. Shi H, Kokoeva MV, Inouye K, Tzameli I, Yin H, Flier JS. TLR4 links innate immunity and fatty acid-induced insulin resistance. J Clin Invest (2006) 116:3015-25. doi:10.1172/JCI28898

38. Suganami T, Tanimoto-Koyama K, Nishida J, Itoh M, Yuan X, Mizuarai S, et al. Role of the toll-like receptor $4 / \mathrm{NF}-\mathrm{kappaB}$ pathway in saturated fatty acid-induced inflammatory changes in the interaction between adipocytes and macrophages. Arterioscler Thromb Vasc Biol (2007) 27:84-91. doi:10.1161/ 01.ATV.0000251608.09329.9a

39. Davis JE, Gabler NK, Walker-Daniels J, Spurlock ME. Tlr-4 deficiency selectively protects against obesity induced by diets high in saturated fat. Obesity (2008) 16:1248-55. doi:10.1038/oby.2008.210

40. Chan KL, Pillon NJ, Sivaloganathan DM, Costford SR, Liu Z, ThéRet M, et al. Palmitoleate reverses high fat-induced proinflammatory macrophage polarization via AMP-activated protein kinase (AMPK). J Biol Chem (2015) 290:16979-88. doi:10.1074/jbc.M115.646992
41. Cao H, Gerhold K, Mayers JR, Wiest MM, Watkins SM, Hotamisligil GS. Identification of a lipokine, a lipid hormone linking adipose tissue to systemic metabolism. Cell (2008) 134:933-44. doi:10.1016/j.cell.2008.07.048

42. Stefan N, Kantartzis K, Celebi N, Staiger H, Machann J, Schick F, et al. Circulating palmitoleate strongly and independently predicts insulin sensitivity in humans. Diabetes Care (2010) 33:405-7. doi:10.2337/dc09-0544

43. Souza CO, Teixeira AA, Lima EA, Batatinha HA, Gomes LM, CarvalhoSilva M, et al. Palmitoleic acid (n-7) attenuates the immunometabolic disturbances caused by a high-fat diet independently of PPARalpha. Mediators Inflamm (2014) 2014:582197. doi:10.1155/2014/582197

44. Prieur X, Mok CY, Velagapudi VR, Nunez V, Fuentes L, Montaner D, et al. Differential lipid partitioning between adipocytes and tissue macrophages modulates macrophage lipotoxicity and M2/M1 polarization in obese mice. Diabetes (2011) 60:797-809. doi:10.2337/db10-0705

45. Camell C, Smith CW. Dietary oleic acid increases M2 macrophages in the mesenteric adipose tissue. PLoS One (2013) 8:e75147. doi:10.1371/journal. pone. 0075147

46. Todoric J, Loffler M, Huber J, Bilban M, Reimers M, Kadl A, et al. Adipose tissue inflammation induced by high-fat diet in obese diabetic mice is prevented by n-3 polyunsaturated fatty acids. Diabetologia (2006) 49: 2109-19. doi:10.1007/s00125-006-0300-x

47. Kalupahana NS, Claycombe K, Newman SJ, Stewart T, Siriwardhana N, Matthan N, et al. Eicosapentaenoic acid prevents and reverses insulin resistance in high-fat diet-induced obese mice via modulation of adipose tissue inflammation. J Nutr (2010) 140:1915-22. doi:10.3945/jn.110.125732

48. Vijay-Kumar M, Vanegas SM, Patel N, Aitken JD, Ziegler TR, Ganji V. Fish oil rich diet in comparison to saturated fat rich diet offered protection against lipopolysaccharide-induced inflammation and insulin resistance in mice. Nutr Metab (Lond) (2011) 8:16. doi:10.1186/1743-7075-8-16

49. Alvheim AR, Torstensen BE, Lin YH, Lillefosse HH, Lock E-J, Madsen L, et al. Dietary linoleic acid elevates endogenous 2-arachidonoylglycerol and anandamide in Atlantic salmon (Salmo salar L.) and mice, and induces weight gain and inflammation in mice. Br J Nutr (2013) 109:1508-17. doi:10.1017/S0007114512003364

50. Porcheray F, Viaud S, Rimaniol AC, Leone C, Samah B, DereuddreBosquet N, et al. Macrophage activation switching: an asset for the resolution of inflammation. Clin Exp Immunol (2005) 142:481-9. doi:10.1111/j. 1365-2249.2005.02934.x

51. Murray PJ, Allen JE, Biswas SK, Fisher EA, Gilroy DW, Goerdt S, et al. Macrophage activation and polarization: nomenclature and experimental guidelines. Immunity (2014) 41:14-20. doi:10.1016/j.immuni.2014.06.008

52. Bellon T, Martinez V, Lucendo B, Del Peso G, Castro MJ, Aroeira LS, et al. Alternative activation of macrophages in human peritoneum: implications for peritoneal fibrosis. Nephrol Dial Transplant (2011) 26:2995-3005. doi:10.1093/ndt/gfq771

53. Rivollier A, He J, Kole A, Valatas V, Kelsall BL. Inflammation switches the differentiation program of Ly6Chi monocytes from antiinflammatory macrophages to inflammatory dendritic cells in the colon. J Exp Med (2012) 209:139-55. doi:10.1084/jem.20101387

54. Kratz M, Coats BR, Hisert KB, Hagman D, Peris E, Schoenfelt KQ, et al. Metabolic dysfunction drives a mechanistically distinct proinflammatory phenotype in adipose tissue macrophages. Cell Metab (2014) 20: 614-25. doi:10.1016/j.cmet.2014.08.010

Conflict of Interest Statement: The authors declare that the research was conducted in the absence of any commercial or financial relationships that could be construed as a potential conflict of interest.

Copyright (๔) 2017 Alshahrani, Bin Khunayfir, Al Rayih, Al Sayed, Alsadoon, Al Dubayee, Zahra, Alrumayyan, Al Zayer, Nasr and Aljada. This is an open-access article distributed under the terms of the Creative Commons Attribution License (CC $B Y$ ). The use, distribution or reproduction in other forums is permitted, provided the original author(s) or licensor are credited and that the original publication in this journal is cited, in accordance with accepted academic practice. No use, distribution or reproduction is permitted which does not comply with these terms. 